\title{
Stability Indicating Assay Method for the Quantitative Determination of Olaparib in Bulk and Pharmaceutical Dosage Form
}

\author{
(1) Antima CHAUDHARY1', (1) Rajiv TONK¹, (1) Pankaj DAGUR², (1) Suddhasattya DEY33, (1) Manik GHOSH²* \\ 1Delhi Pharmaceutical Sciences and Research University, Department of Pharmaceutical Chemistry, New Delhi, India \\ 2Birla Institute of Technology, Department of Pharmaceutical Sciences and Technology, Ranchi, India \\ 3Sanaka Educational Trust's Group of Institutions, Department of Pharmacy, Durgapur West Bengal, India
}

\begin{abstract}
Objectives: Olaparib is an orally active poly (ADP-ribose) PARP (polymerases) inhibitor known to destroy cancer cells with BRCA1 or BRCA2 deficiency. An authentic, fast, distinct, and reliable reverse phase-high performance liquid chromatography (RP-HPLC) method was developed and promptly validated in tablet formulations for olaparib estimation.

Materials and Methods: The proposed method focuses on the separation of olaparib in reverse phase mode using a Waters symmetry $\mathrm{C} 18$ (150 $\mathrm{x}$ $4.6 \mathrm{~mm}, 5 \mu \mathrm{m}$ ) analytical column with a flow rate of $1.0 \mathrm{~mL} / \mathrm{min}$ and the injection volume was kept at $20 \mu \mathrm{L}$. The optimized mobile phase consists of ammonium acetate buffer ( $\mathrm{pH}$ adjusted to 3.5 by glacial acetic acid): methanol in the ratio of 50:50 v/v.

Results: The eluents were measured at $254 \mathrm{~nm}$ and the retention time for the drug encircled was about 4.32 min. The stress degradation studies of olaparib were conducted under acidic, alkaline, oxidative, photolytic and thermal conditions to demonstrate the stability of the drug. The regression value of 0.998 showed that the developed method was linear over the range of $80 \mu \mathrm{g} / \mathrm{mL}$ to $120 \mu \mathrm{g} / \mathrm{mL}$. The developed RP-HPLC method is accurate and precise. The method was statistically validated as per International Conference on Harmonization guidelines.

Conclusion: The proposed method is suitable and can be applied for the quantitative estimation of olaparib without any interference of the excipients used in the drug formulations.
\end{abstract}

Key words: Olaparib, poly ADP-ribose polymerase (PARP) inhibitor, RP-HPLC, waters, ICH and validation

\section{INTRODUCTION}

During the last decade, inactivation of poly (ADP-ribose) polymerase (PARP), a nuclear enzyme associated with many operations including DNA repair and cell death, has emerged as a possible individualized cancer therapeutic approach. ${ }^{1-4}$ In cancer cells with a defective DNA damage repair system, such as those produced by BRCA gene mutations, PARP inhibitors, a new class of anticancer drugs, can cause tumor-specific synthetic lethality. ${ }^{5-8}$ Olaparib (Figure 1), veliparib, niraparib, and rucaparib are potent PARP inhibitors that have recently moved through advanced clinical studies as combination and/ or solo-targeted therapies, especially in breast and ovarian malignancies. Olaparib (Lynparza $\left.{ }^{\circledR}\right)$ was the first medication to be approved for use in individuals with BRCA-mutated ovarian<smiles>O=C(c1cc(Cc2n[nH]c(=O)c3ccccc23)ccc1F)N1CCN(C(=O)C2CC2)CC1</smiles>

Figure 1. Chemical structure of olaparib 
cancer by the European Commission (2014) and the United States Food and Drug Administration (2015).,5,10

PARP inhibitors hold a lot of therapeutic potential and will likely be employed in many cancer therapies in the future. ${ }^{10}$ However, preclinical and clinical studies have revealed that tumor cell sensitivity to PARP inhibitors varies significantly, indicating that treatment efficacy must be enhanced." Because PARP is an intracellular target, a crucial element influencing tumour cell sensitivity and the efficacy of a PARP-targeted treatment is the quantity of PARP inhibitors reaching the intracellular compartment. ${ }^{12}$ PARP inhibitors, like any other intracellular target medicine, are affected by processes such as excretion, metabolism, ${ }^{13}$ drug absorption, and expression/upregulation of transmembrane drug efflux transporters. ${ }^{14,15}$ The latter, which is particularly significant for PARP inhibitors, was discovered as a key resistance mechanism during early preclinical trials. ${ }^{16-18}$

Analytical method validation assures that diverse high performance liquid chromatography (HPLC) analytical procedures provide consistent and reproducible results; it is an important stage in the development of novel dosage forms since it provides information on accuracy, linearity, precision, detection, and quantification limits. "The goal of validation of an analytical procedure is to demonstrate that it is suitable for its intended purpose", according with the International Conference on Harmonization ( $\mathrm{ICH}$ ) guideline. Validation data must now be sent to the appropriate authorities during the medication development process. The validation of analytical methods is governed by a set of guidelines from the $\mathrm{ICH}$ and the United States Pharmacopeia.

Olaparib has not yet been formally included in any of the official pharmacopeias, and there is no documented reverse phase (RP)-HPLC technique for quantifying olaparib in pharmaceutical formulations, according to a comprehensive literature assessment. ${ }^{19,20}$ However, only a few techniques for estimating olaparib concentrations in human plasma using UHPLC10 and liquid chromatography-tandem mass spectrometry (LC-MS/MS) have been reported. ${ }^{21,22}$ This work aimed to create a genuine, quick, distinct, and reliable analytical technique for quantifying olaparib in pharmaceutical formulations using RP-HPLC, which was validated according to ICH guidelines. A proven method for quantifying olaparib in bulk and pharmaceutical formulations was successfully implemented.

\section{MATERIALS AND METHODS}

\section{Chemical and reagents}

The various laboratory batch samples and reference standard (99.92\%) of olaparib were provided by AstraZeneca Pharma. HPLC grade methanol was procured from Merck Sigma-Aldrich. Milli-Q purified water a Milli-Q plus purification system from Millipore was utilized during experimental studies. HPLC grade ammonium acetate was obtained from Rankem.

\section{Instrument}

In the study, a Waters HPLC 2695 sequence with a pump, auto sampler, auto injector, variable wavelength detector, and 2690
PDA detector with thermostatic column compartment was used. Operation control of the instrument and data collection was done by empower 3 software.

\section{Optimization of chromatographic conditions}

The HPLC method was optimized with objective to estimation olaparib in tablet formulation. Several mobile phases in isocratic mode, along with various columns, were considered to achieve a sharp peak with the base line. The tailing factor, the sharpness of the peak, and symmetry were considered for selectivity, sensitivity, and appropriate chromatographic conditions suitable for the column and the mobile phase. Different flow rates were also attempted and fixed at $1 \mathrm{~mL} /$ min for the optimized method. The eluents were also checked for their maximum absorbance in the PDA detector and fixed at $254 \mathrm{~nm}$ as a detection wavelength. The temperature of the column was maintained at $25^{\circ} \mathrm{C}$.

\section{Preparation of mobile phase}

The mobile phase was prepared at a ratio of 50:50 v/v of buffer and methanol. Ammonium acetate buffer was created by dissolving $1.0 \mathrm{~g}$ of ammonium acetate in a sufficient volume of Milli-Q water $(1000 \mathrm{~mL})$. The $\mathrm{pH}$ of the solution was adjusted to 3.5 using glacial acetic acid. The mobile phase was degassed by sonication and it filtered using a $0.45 \mu$ membrane filter. Methanol was used as the diluent. The ultraviolet detector was set at a wavelength of $254 \mathrm{~nm}$.

\section{Preparation of standard solutions}

The standard stock solution of olaparib was prepared by weighing $25 \mathrm{mg}$ olaparib into a $25 \mathrm{~mL}$ volumetric flask, sonicating until dissolved, and finally, the volume was made up to $25 \mathrm{~mL}$ with methanol. Appropriate dilutions were made from the above $1.0 \mathrm{mg} / \mathrm{mL}$ solution and transferred to a 100 $\mathrm{mL}$ volumetric flask, where the final volume was made by the mobile phase. Before the filling the vials for chromatographic analysis, the solution was passed through a membrane filter of diameter $0.45 \mu$.

\section{Sample solution preparation for estimating marketed tablet} formulation

Twenty tablets were accurately weighed, powdered and was added to $25 \mathrm{~mL}$ of diluent in a volumetric flask followed by sonication till it was completely dissolved. Finally, the volume was made up to $50 \mathrm{~mL}$. Appropriate dilution was made to obtain a concentration of $100 \mu \mathrm{g} / \mathrm{mL}$ as a stock solution. Different dilutions were prepared from the stock solution and chromatographic analysis was carried out. Before filling the vial for chromatographic analysis, the solution was filtered via a $0.45 \mu$ membrane filter.

\section{Method validation}

The optimized method developed for olaparib was validated in accordance with the $\mathrm{ICH}$ guideline Q2 (R1) for evaluating linearity, precision, accuracy, specificity, robustness, ruggedness, system suitability, analytical solution stability, and force degradation. 


\section{Linearity}

The linearity range of an analytical method was assessed by injecting the standard dilution in duplicates over five different concentrations made in the range of $80 \mu \mathrm{g} / \mathrm{mL}$ to $120 \mu \mathrm{g} / \mathrm{mL}$. The calibration curve was plotted with the analyte peak area against the analyte concentration to ensure the linearity of the analytical method being developed.

\section{Precision and intermediate precision}

The intra-and inter-day precision was determined in terms of the peak area difference of drug solutions for three consecutive days. A relative standard deviation (RSD) was calculated from the alteration of peak area to represent the intra- and inter-day precision.

Intra- and inter-day precision were performed at three different concentration levels of 80,100 , and $120 \mu \mathrm{g} / \mathrm{mL}$. The repeatability study was performed by injecting six replicates of standard preparations of concentration $100 \mu \mathrm{g} / \mathrm{mL}$.

\section{Accuracy}

The accuracy of the developed method was verified by spiking olaparib, which was performed by spiking olaparib with a standard at three different concentrations: $90 \%, 100 \%$, and $110 \%$. Triplicate analysis of these samples was performed and the results were in the form of RSD\% and recovery percentage.

\section{Specificity}

The specificity of the method was established by analyzing standard substances against potent interferences. Specificity was assessed by injecting standard, sample, placebo, and blank preparations into HPLC. The recovery was measured.

\section{Robustness}

Alterations were made deliberately in chromatographic parameters such as the composition of the mobile phase, mobile phase $\mathrm{pH}$, and flow rate. These variations were evaluated for column efficiency, asymmetry factor along with their RSD\%.

\section{Ruggedness}

Different analysts were considered for the ruggedness study. Solutions of $100 \mu \mathrm{g} / \mathrm{mL}$ were prepared and injected by two different analysts and the result was given in the form of RSD\%.

\section{Assay of standard formulation of lynparza (olaparib)}

Twenty tablets were weighed and crushed to powder. A quantity of this powder equivalent to $50 \mathrm{mg}$ was taken in a 50 $\mathrm{mL}$ volumetric flask to which $25 \mathrm{~mL}$ diluent was added. The solution was sonicated for $30 \mathrm{~min}$, and the volume was adjusted up to the mark with diluent. The solution was further diluted to obtain a concentration of $100 \mu \mathrm{g} / \mathrm{mL}$ of olaparib. Before the filling the vials for chromatographic analysis, the solution was passed through a $0.45 \mu$ membrane filter.

\section{System suitability}

System suitability parameters such as tailing factor, resolution, theoretical plates, and percent RSD were assessed by injecting a blank observed by six replicates of the olaparib standard as well as sample solutions at a concentration of $100 \mu \mathrm{g} / \mathrm{mL}$.
Limit of detection (LOD) and limit of quantification (LOQ)

LOD and LOQ were calculated from the calibration according to the formulas mentioned;

$$
\begin{aligned}
& \mathrm{LOD}=3.3 \mathrm{SD} / \text { Slope } \\
& \mathrm{LOQ}=10 \mathrm{SD} / \text { Slope }
\end{aligned}
$$

or detection limit $=3.3 \mathrm{\sigma} / \mathrm{s}$, quantification limit $=10 \mathrm{\sigma} / \mathrm{s}$, where $\sigma$ is the standard deviation of $y$-intercept of the regression line, and $\mathrm{s}$ is the slope of the calibration curve.

\section{Solution stability}

The stability of the analytical solution was established by injecting the standard solution at a periodic interval of $48 \mathrm{~h}$ by maintaining the temperature of the auto sampler at room temperature. The solution response was measured and the percentage differences in the peak area have been calculated.

\section{Force degradation study}

According to the ICH guideline Q1A (R2), a force degradation study of olaparib was conducted under stress conditions. The olaparib active pharmaceutical ingredient $(100 \mu \mathrm{g} / \mathrm{mL})$ was subjected to hydrolysis (acid and alkali), peroxide, thermal, and photolytic degradation for the stability study.

\section{Acid degradation}

A standard solution of $5 \mathrm{~mL}$ olaparib was taken in a $50 \mathrm{~mL}$ clean and dry volumetric flask. To the volumetric flask, $2.5 \mathrm{~mL}$ of 5 $\mathrm{M} \mathrm{HCl}$ was added and kept for $30 \mathrm{~min}$. After the completion of $30 \mathrm{~min}$, neutralize the solution was with $2.5 \mathrm{~mL}$ of $5 \mathrm{M} \mathrm{NaOH}$ and the $50 \mathrm{~mL}$ volume was made by the mobile phase. Finally, filtering the solution was done with a $0.45 \mu \mathrm{m}$ filter. The filtered solution was introduced into HPLC and the peak area was compared with the standard chromatogram.

\section{Alkali degradation}

A standard solution of $5 \mathrm{~mL}$ olaparib was taken in a $50 \mathrm{~mL}$ clean and dry volumetric flask. To the volumetric flask, $2.5 \mathrm{~mL}$ of $5 \mathrm{M} \mathrm{NaOH}$ was added and kept for $30 \mathrm{~min}$. After $30 \mathrm{~min}$, the solution was neutralized with $2.5 \mathrm{~mL}$ of $5 \mathrm{M} \mathrm{HCl}$, and the mobile phase was responsible for $50 \mathrm{~mL}$ volume. Finally, the prepared solution was filtered with a $0.45 \mu \mathrm{m}$ filter. The filtered solution was introduced into HPLC and the peak area was compared with the standard chromatogram.

\section{Peroxide degradation}

A standard solution of $1.0 \mathrm{~mL}$ olaparib was taken in a $10 \mathrm{~mL}$ clean and dry volumetric flask. To the volumetric flask, $1 \mathrm{~mL}$ of $30 \% \mathrm{H}_{2} \mathrm{O}_{2}$ was added and kept in the flask for $30 \mathrm{~min}$. After the completion of the $30 \mathrm{~min}$, a volume of $10 \mathrm{~mL}$ was made by the mobile phase. Finally, the prepared solution was filtered with a $0.45 \mu \mathrm{m}$ filter. The filtered solution was then introduced into HPLC and the peak area was compared with the standard chromatogram.

\section{Thermal degradation}

The powdered sample of olaparib was spread on a petri dish with $1.0 \mathrm{~mm}$ thickness and kept at $70^{\circ} \mathrm{C}$ in a hot air oven for $3 \mathrm{~h} .25 \mathrm{mg}$ of the sample was taken in a $25 \mathrm{~mL}$ clean and dry 
volumetric flask. $10 \mathrm{~mL}$ solution was pipette out and the volume of $100 \mathrm{~mL}$ was made by the mobile phase. Finally, the prepared solution was filtered with a $0.45 \mu \mathrm{m}$ filter. The filtered solution was introduced into HPLC and the peak area was compared with the standard chromatogram.

\section{Photolytic degradation}

The powdered sample of olaparib was spread on a petri dish $1.0 \mathrm{~mm}$ thickness and kept in direct sunlight for $3 \mathrm{~h} .25 \mathrm{mg}$ of the sample was taken in a $25 \mathrm{~mL}$ clean and dry volumetric flask. $10 \mathrm{~mL}$ solution was pipette out and the volume of $100 \mathrm{~mL}$ was made by the mobile phase. Finally, the prepared solution was filtered with a $0.45 \mu \mathrm{m}$ filter. The filtered solution was introduced into HPLC and the peak area was compared with the standard chromatogram.

\section{Statistical analysis}

Statistical data were not used during the experiments.

\section{RESULTS}

\section{Method development}

\section{Chromatographic separation}

Various chromatographic systems (RP-HPLC) were considered to optimize the separation of olaparib. Olaparib separation was performed on the column C18 (150 mm x $4.6 \mathrm{~mm}, 5 \mu \mathrm{m}$ ). The mobile phase was a combination that included $500 \mathrm{~mL}$ methanol, $500 \mathrm{~mL}$ buffer, and $1.0 \mathrm{~mL}$ of glacial acetic acid, $\mathrm{pH}$ adjusted to $3.5 \pm 0.05$ with ammonium acetate. The flow rate was set to $1.0 \mathrm{~mL} / \mathrm{min}$ and the detector was set to $254 \mathrm{~nm}$. The injection volume was kept at $20 \mu \mathrm{L}$. The retention time for olaparib was found to be 4.32 min as shown in Figure 2.

\section{Calibration curve}

The calibration curve was prepared and evaluated using the least square method within the Microsoft Excel ${ }^{\circledR}$ program. The coefficient of determination $\left(R^{2}\right)$, slope and intercept for olaparib were $0.998,23599$, and 66731 , respectively. The linear equation was found to be $y=23599 x+66731$ and the calibration curve is shown in Figure 2.

\section{Validation of the method}

\section{Linearity}

The analytical calibration curve was plotted for olaparib and was found to be linear in the specified ranges $(80-120 \mu \mathrm{g} / \mathrm{mL}$ ) indicating a correlation coefficient $R^{2}$ of 0.99 (acceptance limit >0.98). The slope of the straight line was found to be 23599 and the intercept was found to be 66731. The results are reported in Table 1 and the calibration curve is shown in Figure 2.

\section{Precision and intermediate precision}

The precision value was reported in terms of RSD\%. The RSD\% for olaparib was found to be $\langle 2.0 \%$ for both inter- and intra-day precision, indicating satisfactory precision (Table 2). The interday precision was found to be within $0.05-0.98$, whereas intraday precision was found to be within 0.06-0.43.

\section{Accuracy}

The accuracy of this method is determined by a recovery study conducted using standard addition methods at six concentration levels, first $90 \%, 100 \%$, and $110 \%$. The spiked sample solutions were assayed in triplicate and the obtained results were compared with the expected results and expressed as the

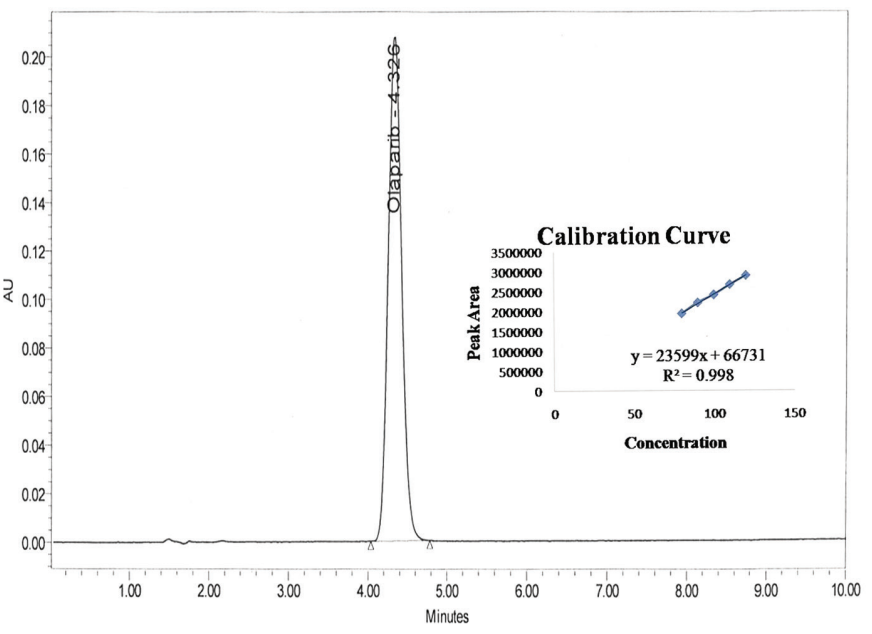

Figure 2. HPLC chromatogram of olaparib at $254 \mathrm{~nm}$. Inset: Calibration curve of olaparib

HPLC: High performance liquid chromatography

Table 1. Linear regression equation generated from validation of olaparib: Slope, intercept, and coefficient of determination

\begin{tabular}{|c|c|c|c|c|c|}
\hline Concentration & Concentration & Peak & Peak area & Peak area & Average \\
\hline$(\mathrm{mg} / \mathrm{mL})$ & $(\mu \mathrm{g} / \mathrm{mL})$ & Area 1 & 2 & 3 & Area \\
\hline 0.080 & 80 & 1938729 & 1945764 & 1942428 & 1942307 \\
\hline 0.100 & 100 & 2413316 & 2411985 & 2415423 & 2413575 \\
\hline 0.110 & 110 & 2671899 & 2672202 & 2663858 & 2669319.600 \\
\hline Slope & - & - & - & - & 23599 \\
\hline Intercept & - & - & - & - & 66731 \\
\hline $\mathrm{R}^{2}$ (correlation) & (Coefficient) & - & - & - & 0.998 \\
\hline
\end{tabular}


percentage of recovery reported in Table 3. The recovery was found to be within the limit.

\section{Specificity}

The developed analytical method should reflect that there was no interference due to the presence of excipients in the formulation. The recovery and RSD\% of olaparib were measured and were within the limits summarized in Table 4. The recovery was found to be 100.81-101.71 and RSD\% was within 0.10-0.80.

\section{Robustness}

The method was found to be robust, ensuring that upon applying small variations to the chromatographic conditions in terms of flow rate, mobile phase composition, and $\mathrm{pH}$ variation in the mobile phase, no significant changes are detected. The robustness data were expressed in terms of RSD\% was found to be 0.68 and is given in Table 5 .

\section{Ruggedness}

Analyst 1 and analyst 2 performed the ruggedness test and the results are summarized in Table 6 as RSD\% was found to be 1.48 .

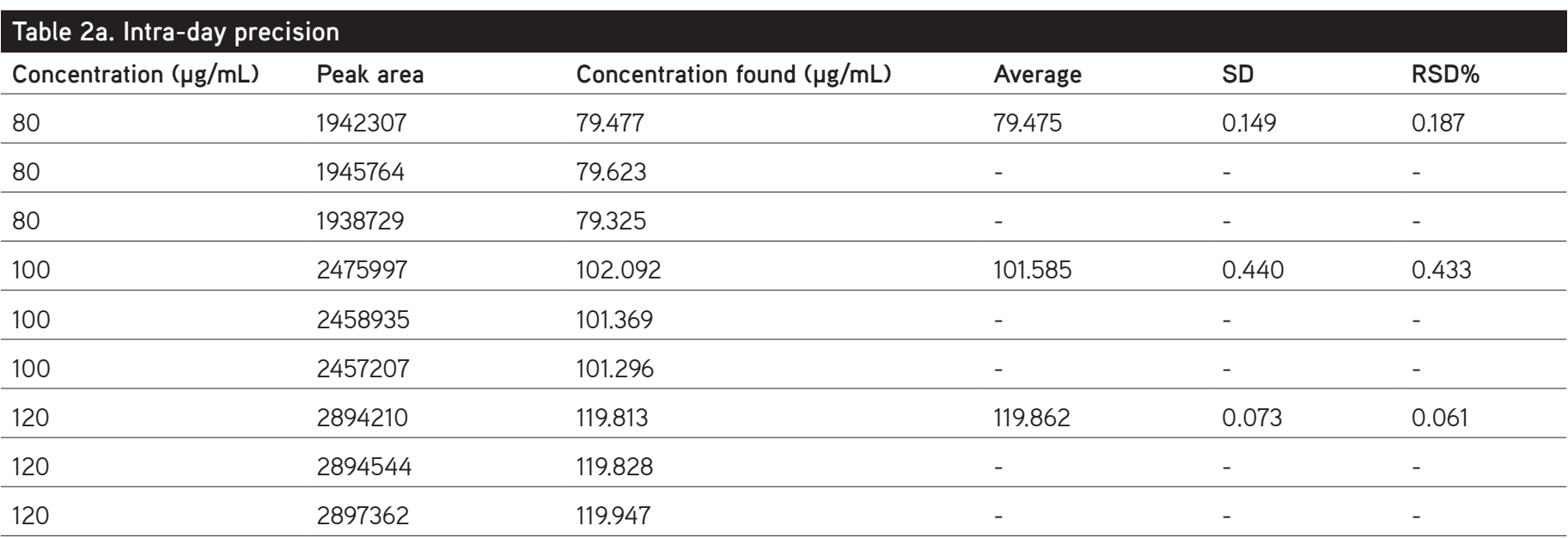

SD: Standard deviation (n: 3), RSD: Relative standard deviation

Table 2 b. Inter-day precision

\begin{tabular}{|c|c|c|c|c|c|}
\hline Concentration $(\mu \mathrm{g} / \mathrm{mL})$ & Peak area & Concentration found $(\mu \mathrm{g} / \mathrm{mL})$ & Average & SD & RSD $\%$ \\
\hline 80 & 1939789 & 79.370 & 79.417 & 0.043 & 0.054 \\
\hline 80 & 1941781 & 79.455 & - & - & - \\
\hline 80 & 1941161 & 79.428 & - & - & - \\
\hline 100 & 2442327 & 100.665 & 101.802 & 1.005 & 0.986 \\
\hline 120 & 2894277 & 119.816 & 119.868 & 0.157 & 0.131 \\
\hline 120 & 2892563 & 119.743 & - & - & - \\
\hline 120 & 2899665 & 120.044 & - & - & - \\
\hline
\end{tabular}

SD: Standard deviation (n: 3), RSD: Relative standard deviation

Table 2c. Repeatability

\begin{tabular}{llllll} 
Concentration $(\mu \mathrm{g} / \mathrm{mL})$ & Peak area & Concentration found $(\mu \mathrm{g} / \mathrm{mL})$ & Average & SD & RSD\% \\
\hline 100 & 2443258 & 100.704 & 100.959 & 0.250 & - \\
\hline 100 & 2448178 & 100.913 & - & - & - \\
\hline 100 & 2446070 & 100.824 & - & - & - \\
\hline 100 & 2444889 & 100.774 & - & - & - \\
\hline 100 & 2457432 & 101.305 & - & - & - \\
\hline 100 & 2455724 & 101.232 & - & & -
\end{tabular}

SD: Standard deviation, RSD: Relative standard deviation 


\section{System suitability}

The system suitability test is an important element of chromatographic analysis since it ensures that the chromatographic system's accuracy and repeatability are sufficient for analysis. It was performed with six replicate injections of the standard solution of olaparib. The retaining of olaparib was found to be 4.32 min, having a tailing factor of not more than 1.17 in all peaks, indicating good peak symmetry. Theoretical plates were found to be 3160 . The results are reported in Table 7.

\section{Detection limit and quantification limit}

The LOD and LOQ of olaparib were found to be $0.49 \mu \mathrm{g} / \mathrm{mL}$ and $1.49 \mu \mathrm{g} / \mathrm{mL}$, respectively.

\section{Assay of standard formulation of lynparza (olaparib)}

Assay validation provides reliability assurance during normal use, and is sometimes referred to as "the process of providing documented evidence that the method is doing what it intends to do". The purity by HPLC is determined by the percentage recovery of olaparib. The developed method was very accurate, precise and robust as recovery percentage was within $100 \pm 2$ given in Figure $3 \mathrm{a}$ and Table 8.

\section{Analytical solution stability}

The olaparib sample solution was stable for $24 \mathrm{~h}$ at room temperature. The stability results were analyzed for the percentage difference from zero time injection, where there was no decrease in the peak areas of the drug nor a shifting of retention time was detected. The observations obtained from the stability phenomenon are reported in Table 9.

\section{Force degradation study}

The drug degradation study was conducted in acid, alkaline, and oxidation solutions to determine the stability of the drug under different conditions.

\section{Acid degradation}

The acid degradation of olaparib was carried out at different concentrations of (1-5 M) $\mathrm{HCl}$ until it was degraded for a period of $30 \mathrm{~min}$. The degraded chromatogram and the nondegraded chromatogram were compared and the percentage of degradation was calculated. The chromatogram is given in (Figure $3 b$ ) and the results are summarized in Table 10. Acid degradation was found to be $12.69 \%$ for $5 \mathrm{M} \mathrm{HCl}$.

\begin{tabular}{|c|c|c|c|c|c|}
\hline Recovery level & API added (mg) & API recovered $(\mathrm{mg})$ & Recovery\% & Average recovery\% & RSD\% \\
\hline $90 \%$ & - & 22.110 & 98.680 & - & - \\
\hline $90 \%$ & - & 22.500 & 100.390 & - & - \\
\hline $100 \%$ & - & 24.720 & 99.290 & - & - \\
\hline $100 \%$ & - & 25.060 & 100.000 & - & - \\
\hline $110 \%$ & - & 26.920 & 98.300 & - & - \\
\hline $110 \%$ & 24.900 & 26.900 & 98.220 & 98.260 & 0.050 \\
\hline $110 \%$ & - & 26.870 & 98.110 & - & - \\
\hline
\end{tabular}

RSD: Relative standard deviation, API: Active pharmaceutical ingredient

Table 4. Specificity table of olaparib

\begin{tabular}{|c|c|c|c|c|c|c|c|}
\hline Analyte & Added $\%$ & $\begin{array}{l}\text { Excipient amount } \\
\text { added (mg) }\end{array}$ & $\begin{array}{l}\text { Concentration found } \\
(\mu \mathrm{g} / \mathrm{mL})\end{array}$ & Recovery\% & Average recovery\% & SD & RSD\% \\
\hline Olaparib & 50 & 5 & 100.705 & 100.705 & 100.814 & 0.105 & 0.104 \\
\hline \multirow{6}{*}{$(10 \mathrm{mg})$} & 50 & 5 & 100.824 & 100.824 & - & - & - \\
\hline & 100 & 10 & 100.774 & 100.774 & 100.915 & 0.342 & 0.340 \\
\hline & 100 & 10 & 100.665 & 100.665 & - & - & - \\
\hline & 150 & 15 & 102.569 & 102.57 & 101.710 & 0.892 & 0.877 \\
\hline & 150 & 15 & 100.789 & 100.789 & - & - & - \\
\hline & 150 & 15 & 101.773 & 101.774 & - & - & - \\
\hline
\end{tabular}

SD: Standard deviation, RSD: Relative standard deviation 


\section{Alkali degradation}

The alkali degradation of olaparib was carried out at different concentrations of (1-5 M) NaOH until it was degraded. The degraded chromatogram and the non-degraded chromatogram were compared and the percentage of degradation was calculated. The chromatogram is given in Figure $4 \mathrm{a}$ and the results are summarized in Table 9. Alkali degradation was found to be $2.60 \%$ at $5 \mathrm{M} \mathrm{NaOH}$.

\section{Peroxide degradation}

Peroxide degradation of olaparib was carried out at a concentration of $30 \%$. A comparative study of the peroxide degraded olaparib chromatogram and the non-degraded chromatogram was conducted to calculate the $2.55 \%$ degradation. The chromatogram is given in Figure $4 \mathrm{~b}$ and the results are summarized in Table 10.

\section{Thermal degradation}

Thermal degradation of the drug was found to be negligible. The olaparib drug was found to be thermal stable as there was no degradation when exposed to thermal conditions. The chromatogram is given in Figure $5 \mathrm{a}$, and the results are summarized in Table 10.

\section{Photolytic degradation}

Degradation by photolysis of olaparib was found to be negligible. The olaparib drug was found to be light stable as there was no degradation when exposed to light. The chromatogram is given in (Figure 5b) and the results are summarized in Table 10.

\section{DISCUSSION}

Olaparib is a new drug, so almost no method is available to estimate olaparib in bulk and pharmaceutical dosage form. Therefore, our present aim was to develop a new, compatible, stable, robust method for the determination of olaparib in bulk and formulations by RP-HPLC.

According to the $\mathrm{ICH}$ guidelines, the developed method was validated for the following parameters: system suitability, linearity, accuracy, precision, robustness, and analytical

\section{Table 5. Robustness study with flow rate, $\mathrm{pH}$, and mobile phase composition}

\begin{tabular}{|c|c|c|c|c|c|c|c|}
\hline $\begin{array}{l}\text { Sample } \\
\text { ID }\end{array}$ & Analytical condition & $\begin{array}{l}\text { Olaparib } \\
\text { input (mg) }\end{array}$ & $\begin{array}{l}\text { Olaparib } \\
\text { recovery }(\mathrm{mg})\end{array}$ & $\begin{array}{l}\text { Olaparib } \\
\text { recovery (\%) }\end{array}$ & $\begin{array}{l}\text { Mean recovery } \\
\text { olaparib }(\%)\end{array}$ & SD & RSD\% \\
\hline \multirow{4}{*}{1} & Flow rate: $1.1 \mathrm{~mL} / \mathrm{min}$ & \multirow{4}{*}{25} & \multirow{4}{*}{24.860} & \multirow{4}{*}{99.500} & 100.060 & 0.680 & 0.680 \\
\hline & Mobile phase $\mathrm{pH}: 3.5$ & & & & & & \\
\hline & Mobile phase ratio: 50:50 & & & & & & \\
\hline & Column: C18 (150 mm x $4.6 \mathrm{~mm}, 5 \mu \mathrm{m})$ & & & & & & \\
\hline \multirow{4}{*}{2} & Flow rate: $0.9 \mathrm{~mL} / \mathrm{min}$ & \multirow{4}{*}{25} & \multirow{4}{*}{25.090} & \multirow{4}{*}{100.300} & & & \\
\hline & Mobile phase $\mathrm{pH}: 3.5$ & & & & & & \\
\hline & Mobile phase ratio: $50: 50$ & & & & & & \\
\hline & Column: C18 (150 mm x $4.6 \mathrm{~mm}, 5 \mu \mathrm{m})$ & & & & & & \\
\hline \multirow{4}{*}{3} & Flow rate: $1 \mathrm{~mL} / \mathrm{min}$ & \multirow{4}{*}{25} & \multirow{4}{*}{24.820} & \multirow{4}{*}{99.200} & & & \\
\hline & Mobile phase pH: 3.6 & & & & & & \\
\hline & Mobile phase ratio: 50:50 & & & & & & \\
\hline & Column: C18 (150 mm x $4.6 \mathrm{~mm}, 5 \mu \mathrm{m})$ & & & & & & \\
\hline \multirow{4}{*}{4} & Flow rate: $1 \mathrm{~mL} / \mathrm{min}$ & \multirow{4}{*}{25} & \multirow{4}{*}{25.110} & \multirow{4}{*}{100.400} & & & \\
\hline & Mobile phase $\mathrm{pH}: 3.4$ & & & & & & \\
\hline & Mobile phase ratio: 50:50 & & & & & & \\
\hline & Column: C18 (150 mm x $4.6 \mathrm{~mm}, 5 \mu \mathrm{m})$ & & & & & & \\
\hline \multirow{4}{*}{5} & Flow rate: $1 \mathrm{~mL} / \mathrm{min}$ & \multirow{4}{*}{25} & \multirow{4}{*}{24.980} & \multirow{4}{*}{99.900} & & & \\
\hline & Mobile phase $\mathrm{pH}: 3.5$ & & & & & & \\
\hline & Mobile phase ratio: 55:45 & & & & & & \\
\hline & Column: C18 (150 mm x $4.6 \mathrm{~mm}, 5 \mu \mathrm{m})$ & & & & & & \\
\hline \multirow{4}{*}{6} & Flow rate: $1 \mathrm{~mL} / \mathrm{min}$ & \multirow{4}{*}{25} & \multirow{4}{*}{25.290} & \multirow{4}{*}{101.100} & & & \\
\hline & Mobile phase pH: 3.5 & & & & & & \\
\hline & Mobile phase ratio: $45: 55$ & & & & & & \\
\hline & Column: C18 (150 mm x $4.6 \mathrm{~mm}, 5 \mu \mathrm{m})$ & & & & & & \\
\hline
\end{tabular}


solution stability. The RSD\% value was well below 2 and the percentage recovery was within the limit of $100 \pm 2$. The stability of the drugs is a immense issue during formulation and still no
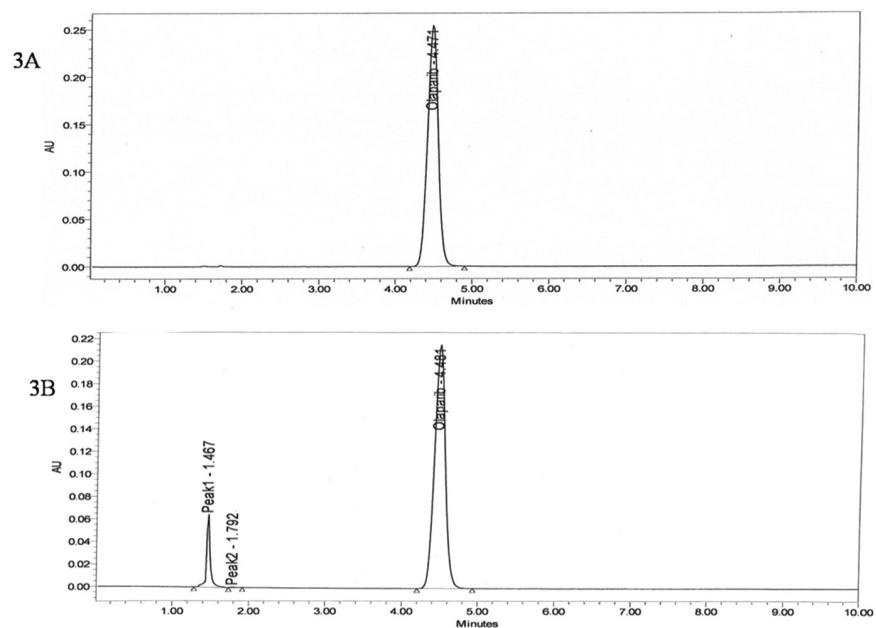

Figure 3. A) Chromatogram showing assay of standard formulation, B) Chromatogram of acid-degraded olaparib
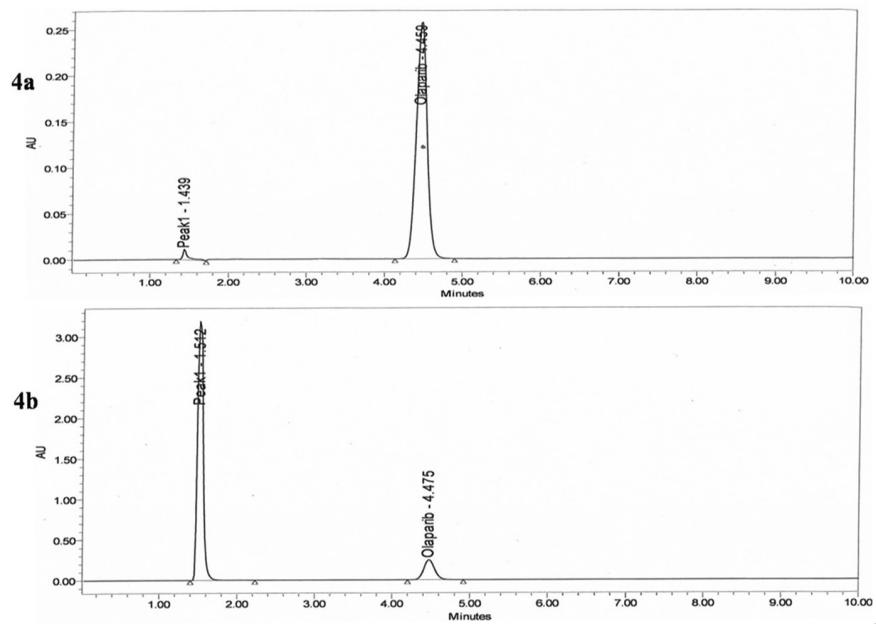

Figure 4. a) Chromatogram of base degraded olaparib, b) Chromatogram of hydrogen peroxide degraded olaparib
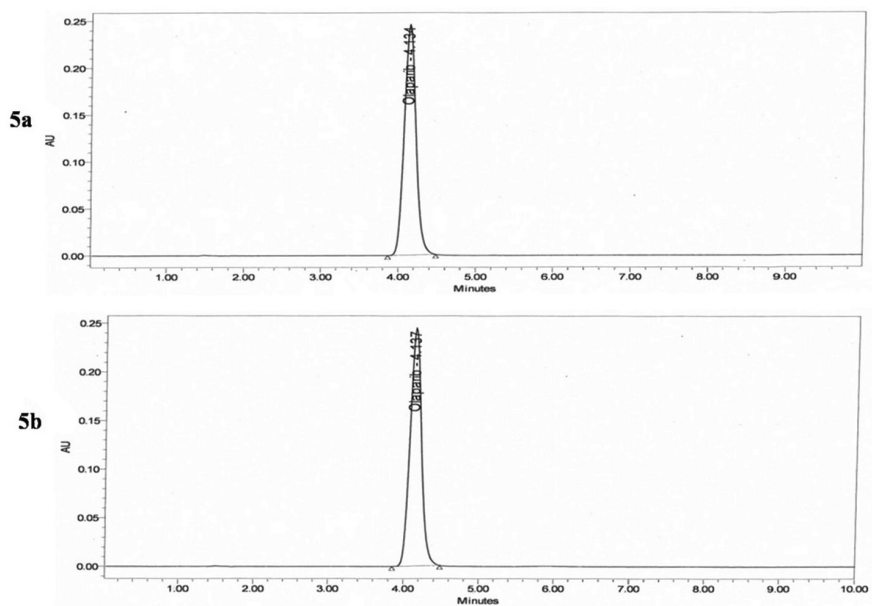

Figure 5. a) Chromatogram of thermal degraded olaparib, b) Chromatogram of photolytic degraded olaparib stability data have been reported. To determine the stability of olaparib, we conducted a force degradation study.

The drug was found to be very stable, when exposed to heat and light. It was also found to be quite stable under both acidic and basic conditions. Higher concentrations of acids and bases ( $5 \mathrm{M}$ ) could degrade the drug, too, by $12.69 \%$ under acidic conditions, whereas in the case of basic and oxidation

\section{Table 6. Ruggedness of olaparib}

\begin{tabular}{llll} 
S. no. & $\begin{array}{l}\text { Analyst 1 } \\
\text { (assay\%) }\end{array}$ & $\begin{array}{l}\text { Assay percent } \\
\text { olaparib }\end{array}$ & $\begin{array}{l}\text { Analyst 2 } \\
\text { (assay\%) }\end{array}$ \\
\hline 1 & 99.390 & 100.560 \\
\hline 2 & 100.210 & 99.640 \\
\hline 3 & 98.040 & 99.800 \\
\hline 4 & 102.690 & 100.410 \\
\hline 5 & 99.980 & 100.200 \\
\hline 6 & 101.560 & 97.100 \\
\hline Mean & 100.480 & 99.620 \\
\hline $\begin{array}{l}\text { RSD\% } \\
\text { Overall percentage }\end{array}$ & 1.660 & 1.480 & 1.290 \\
RSD & & & \\
\hline
\end{tabular}

RSD: Relative standard deviation

Table 7. System suitability parameters and achieved values parameters

Values achieved in the validation phenomenon

\begin{tabular}{ll}
\hline Theoretical plates & 3160 \\
\hline Retention time & 4.32 minutes \\
\hline Asymmetry & 1.170 \\
\hline RSD & $0.240 \%$ \\
\hline
\end{tabular}

RSD: Relative standard deviation

\section{Table 8. Summery of validation}

\begin{tabular}{lll} 
Parameter & Acceptable limit & Remark \\
\hline Accuracy & $98.260-99.680$ & Passed \\
\hline Specificity & $0.100-0.800$ & Passed \\
\hline Precision & $0.056-0.980$ & Passed \\
\hline Linearity & 0.998 & Passed \\
\hline Ruggedness and Robustness & 1.480 and 0.680 & Passed \\
\hline Assay & $98.680 \%$ & Passed \\
\hline
\end{tabular}

\section{Table 9. Solution stability data}

\begin{tabular}{llllll} 
Time & Inject & Time & $\begin{array}{l}\text { Difference } \\
\text { (sec) }\end{array}$ & Area & Calculation \\
\hline Initial & 9 & 2 & 0 & 2442536 & 0.00 \\
\hline After 1 h & 10 & 9 & 67 & 2450664 & 0.00 \\
\hline After 24 h & 10 & 5 & 1436 & 2473824 & -0.01 \\
\hline
\end{tabular}


Table 10. Force degradation data

\begin{tabular}{llll} 
Type of degradation & Area & Degradation $\%$ & Peak purity \\
\hline No degradation (standard chromatogram $100 \mu \mathrm{g} / \mathrm{mL})$ & 2443258 & - & Passed \\
\hline $2.5 \mathrm{~mL}$ of $5 \mathrm{M} \mathrm{HCl}$ (acidic) & 2133134.666 & 12.690 & Passed \\
\hline $2.5 \mathrm{~mL} 5 \mathrm{M} \mathrm{NaOH}$ (alkaline) & 2507018.666 & 2.600 & Passed \\
\hline $1 \mathrm{~mL}$ of $30 \% \mathrm{H}_{2} \mathrm{O}_{2}$ (peroxide) & 2380875 & 2.550 & Passed \\
\hline Thermal degradation & 2443258 & 0 & Passed \\
\hline Photolytic degradation & 2443258 & 0 & Passed \\
\hline
\end{tabular}

conditions, degradation was found to be $2.60 \%$ and $2.55 \%$. Under thermal and photolytic conditions, they were found to be stable.

\section{CONCLUSION}

The developed method in RP-HPLC was established to be simple, cost-effective, accurate, and robust; so that, it can be extensively applied for estimating any formulations of olaparib. This degradation study was conducted on HPLC for the first time. As the HPLC method is less cost-effective compared with the LC-MS method, this will prove an effective method for estimating olaparib.

Degradation studies were conducted and from the study we can conclude that the degradation of olaparib was very low in the case of basic and oxidation conditions, whereas in the case of acidic degradation by $\mathrm{HCl}$, the highest degradation was observed. The degradation was found to be $12.69 \%$. No degradations were found in the case of thermal and photolytic conditions. The drug olaparib can be considered a very stable drug in all conditions except the acidic condition.

\section{ACKNOWLEDGMENTS}

The authors are grateful to the Department of Delhi Pharmaceutical Sciences and Research University, New Delhi (India) for providing the facilities for working and to the laboratory assistance.

Ethics

Ethics Committee Approval: Not applicable.

Informed Consent: Not applicable.

Peer-review: Externally peer-reviewed.

\section{Authorship Contributions}

Concept: A.C., R.T., Design: A.C., R.T., S.D., Data Collection or Processing: A.C., P.D., Analysis or Interpretation: M.G., S.D., A.C., P.D., Literature Search: A.C., P.D., Writing: M.G., S.D., A.C., P.D.

Conflict of Interest: No conflict of interest was declared by the authors.

Financial Disclosure: The authors declared that this study received no financial support.

\section{REFERENCES}

1. Dizdar O, Arslan C, Altundag K. Advances in PARP inhibitors for the treatment of breast cancer. Expert Opin Pharmacother. 2015;16:27512758.

2. Ferraris DV. Evolution of poly(ADP-ribose) polymerase-1 (PARP-1) inhibitors. From concept to clinic. J Med Chem. 2010;53:4561-4584.

3. Lupo B, Trusolino L. Inhibition of poly(ADP-ribosyl)ation in cancer: old and new paradigms revisited. Biochim Biophys Acta. 2014;1846:201-215.

4. Schreiber V, Dantzer F, Ame JC, de Murcia G. Poly(ADP-ribose): novel functions for an old molecule. Nat Rev Mol Cell Biol. 2006;7:517-528.

5. Brown JS, Kaye SB, Yap TA. PARP inhibitors: the race is on. Br J Cancer. 2016;114:713-715.

6. Murai J, Huang SY, Das BB, Renaud A, Zhang Y, Doroshow JH, Ji J, Takeda S, Pommier Y. Trapping of PARP1 and PARP2 by clinical PARP inhibitors. Cancer Res. 2012;72:5588-5599.

7. Tangutoori S, Baldwin P, Sridhar S. PARP inhibitors: a new era of targeted therapy. Maturitas. 2015;81:5-9.

8. Murata S, Zhang C, Finch N, Zhang K, Campo L, Breuer EK. Predictors and modulators of synthetic lethality: an update on PARP inhibitors and personalized medicine. Biomed Res Int. 2016;2016:2346585.

9. Deeks ED. Olaparib: first global approval. Drugs. 2015;75:231-240.

10. O'Connor MJ. Targeting the DNA damage response in cancer. Mol Cell. 2015;60:547-560.

11. Dollery CT. Intracellular drug concentrations. Clin Pharmacol Ther. 2013;93:263-266.

12. Fojo T, Bates S. Mechanisms of resistance to PARP inhibitors-three and counting. Cancer Discov. 2013;3:20-23.

13. Lord CJ, Ashworth A. Mechanisms of resistance to therapies targeting BRCA-mutant cancers. Nat Med. 2013;19:1381-1388.

14. Dufour R, Daumar P, Mounetou E, Aubel C, Kwiatkowski F, Abrial C, Vatoux C, Penault-Llorca F, Bamdad M. BCRP and P-gp relay overexpression in triple negative basal-like breast cancer cell line: a prospective role in resistance to olaparib. Sci Rep. 2015;5:12670.

15. Aoki D, Chiyoda T. PARP inhibitors and quality of life in ovarian cancer. Lancet Oncol. 2018;19:1012-1014.

16. Weil MK, Chen AP. PARP inhibitor treatment in ovarian and breast cancer. Curr Probl Cancer. 2011;35:7-50.

17. Faraoni I, Aloisio F, De Gabrieli A, Consalvo MI, Lavorgna S, Voso MT, LoCoco F, Graziani G. The poly(ADP-ribose) polymerase inhibitor olaparib induces up-regulation of death receptors in primary acute myeloid leukemia blasts by NF-KB activation. Cancer Lett. 2018;423:127-138. 
18. Liu CH, Chang Y, Wang PH. Poly(ADP-ribose) polymerase (PARP) inhibitors and ovarian cancer. Taiwan J Obstet Gynecol. 2017;56:713-714.

19. Nijenhuis CM, Lucas L, Rosing H, Schellens JH, Beijnen JH. Development and validation of a high-performance liquid chromatography-tandem mass spectrometry assay quantifying olaparib in human plasma. J Chromatogr B Analyt Technol Biomed Life Sci. 2013;940:121-125.

20. Daumar P, Dufour R, Dubois C, Penault-Llorca F, Bamdad M, Mounetou E. Development and validation of a high-performance liquid chromatography method for the quantitation of intracellular PARP inhibitor olaparib in cancer cells. J Pharm Biomed Anal. 2018;152:74-80.
21. Roth J, Peer CJ, Mannargudi B, Swaisland H, Lee JM, Kohn EC, Figg WD. A sensitive and robust ultra HPLC assay with tandem mass spectrometric detection for the quantitation of the PARP inhibitor olaparib (AZD2281) in human plasma for pharmacokinetic application. Chromatography. 2014;1:82-95.

22. Nijenhuis $\mathrm{CM}$, Rosing $\mathrm{H}$, Schellens JH, Beijnen JH. Development and validation of a high-performance liquid chromatography-tandem mass spectrometry assay quantifying vemurafenib in human plasma. J Pharm Biomed Anal. 2014;88:630-635. 